\title{
A study investigating the association between vitamin $D$ and depression among university students in 39 countries.
}

\author{
Dania Abdul Razzak Kouider ${ }^{1}$, Nageeb Abdul Galil Hassan ${ }^{1}$, Yaser Mohammed Al-Worafi ${ }^{1,2 *}$ \\ ${ }^{1}$ College of Pharmacy and Health Sciences, Ajman University, Ajman, UAE \\ ${ }^{2}$ College of Pharmacy, University of Science and Technology of Fujairah, Fujairah, UAE
}

\begin{abstract}
Objectives: The aim of this study was to explore the association between vitamin D deficiency and depression among university students and to identify the factors affecting this association.

Methodology: A cross-sectional study was conducted between 1st January and end of March 2017 among university students from 39 different countries.

Results: 699 students were participated in this study. The findings of this study found that 270 students (38.6\%) had vitamin D deficiency with level less than 20 . The findings of this study found that majority of students $(\mathbf{9 9 . 9 \%})$ in this study had depression. The findings of this study found that there was no association between depression and vitamin $D$ depression ( $p$ value $=0.386$ ). The findings of this study shows that there was a significant difference between the severe groups of depression and other classes in terms of prevalence of vitamin $D$ deficiency ( $p$ value $=0.000$ ).

Conclusion: The current study shows that there was no association between vitamin $D$ deficiency and depression. On the other hand, there were significant associations between the severity of depression and vitamin D deficiency. Lack of sun exposure; diet and financial factors were the causes of vitamin D deficiency in this study. Further studies are highly recommended to investigate the causes of depression among students.
\end{abstract}

Keywords: Vitamin D, Deficiency, Depression, Students.

Accepted on June 5, 2019

\section{Introduction}

Vitamin D deficiency affecting about half of the population worldwide [1-3]. Vitamin D deficiency affects all races as well as all age groups from infants till elderly [1-3]. Vitamin D deficiency is a serious health problem and associated with death in the general population [4]. Vitamin D deficiency reported as one of many risk factors that may cause depression $[5,6]$. Vitamin D supplementation may have a positive effect on the management of depression as they contribute to the neuroendocrine system regulation [7]. Across sectional study conducted by Jorde et al. [8] to investigate the association between vitamin $\mathrm{D}$ deficiency and depression as well as to evaluate the impact of vitamin $\mathrm{D}$ supplementation on the depression among 445 out patients at the University Hospital of North Norway found that there was a significant association between vitamin deficiency and depression. They found also that the vitamin D supplementation improved the depression symptoms [8]. Another study conducted by Guixiang et al. among 3916 adult's patients in US found that there was no significant association between vitamin D deficiency and depression [5]. There are many factors contributing to the Vitamin D deficiency as reported in the literature: insufficient sun exposure on of the most important causes of Vitamin D deficiency; lack and insufficient amount of Vitamin D in the diet; Vitamin D malabsorption problems and others [6-8]. Depression is defined by American Psychiatric Association as: "a common and serious medical illness that negatively affects how you feel, the way you think and how you act" [9]. Identification and management of Vitamin D deficiency among patients with depression are easy, not expensive, cost effective and may contribute to achieve the desired outcomes of treating patients with depression which lead to improve their quality of life [10].

There are few studies worldwide exploring the association between depression and Vitamin D deficiency. Therefore, the aim of this study was to explore the association between vitamin D deficiency and depression among university students.

\section{Methods}

\section{Study design}

A cross-sectional study was conducted between 1st January and end of march 2017 among university students from the following countries: USA, Canada, Belgium, Russia, Sweden, 
France, UK, Finland, Germany, Norway, Italy, Romania, Greece, Ireland, Austria, Denmark, Switzerland, turkey, Slovenia, Netherlands, Egypt, Algeria, Sudan, Iraq, Morocco, Saudi Arabia, Yemen, Syria, Tunisia, Somalia, UAE, Jordan, Libya, Palestine, Lebanon, Oman, Kuwait, Bahrain, and Mauritania.

\section{Sample size and sampling technique}

The sample size (n) was calculated based on Cochran equation. The calculated sample size was 385 . Convenience sampling technique was uses in this study. 800 university students from different countries were invited to participate in this study.

\section{Study instrument and data collection}

Self-administered questionnaire was adapted from the literature $[11,12]$. The questionnaire is divided into three parts: First part of the questionnaire consisted of participant's data: gender, age, study specialty (medical or non), level of study, marital status and country. Second part about Vitamin D related questions. We used Vitamin D cutoff level of 20 as an indicator for vitamin D deficiency. Third part was aimed to explore the depression status among participants. Nine questions were adapted from PHQ-9 evaluation checklist and used in this study $[11,12]$. Checklist was distributed to 10 students from UAE to check the clarity of questions. Scoring system was used in part three. For each question participants were asked to select one of the following four answers: "Not at all", "Several days", "More than half the days", and "Nearly every day". Zero score was giving to Not at all answer; 1 score was giving to Several days' answer; 2 scores was giving to More than half the day's answer and score 3 was giving to Nearly every day answer. Interpretation of Total Scores as following: Minimal depression (1-4 scores); mild depression for (5-9 scores); moderate depression for (10-14 scores); moderately severe depression for (15-19 scores) and severe depression for (20-27 scores).

\section{Ethical considerations}

This study was approved from Ajman University. Consent was obtained from the participant's. No personal information of the patients was collected.

\section{Statistical analysis}

The data were descriptively analyzed using Statistical Package for the Social Sciences ${ }^{\circledR}$ (IBM SPSS) version 21 for Windows. Differences in proportional were tested with Chi-square test or Fisher's Exact test and Pearson Chi-square. The result is significant if $\mathrm{P}$-value is $\leq 0.05$.

\section{Results}

The response rate was high in this study as 699 out 800 of the distributed questionnaires was completed. The majority of respondents were female $(53.8 \%, n=376)$. About $62 \%(n=351)$ of the respondents were younger than 24 years old.365 (37.9\%) participants graduated or learned at medical school. Majority of participants are singles $(78 \%, n=345)$. Majority of participants in this study from Levant and Iraq $(37.5 \%, n=262)$, followed by Europe $(25.3 \%, \mathrm{n}=177)$, then 144 students from Gulf countries (16.3\%), Africa $(10.4 \%, \mathrm{n}=73)$, Turkey and Cyprus $(8.4 \%, \mathrm{n}=59)$ and few participants from USA and Canada $(2 \%, n=14)$.

\section{Prevalence of Vitamin D deficiency}

270 students $(38.6 \%)$ had vitamin D deficiency with level less than 20. The findings of this study shows that there was a significant difference between males and females in terms of prevalence of vitamin $D$ deficiency ( $p$ value $=0.001$ ). Female students had more vitamin D deficiency prevalence $(61.5 \%)$ than males $(38.5 \%)$. The findings of this study shows that there was a significant difference between medical students and nonmedical students in terms of prevalence of vitamin D deficiency $(p$ value $=0.010)$. Non-medical students had more vitamin $\mathrm{D}$ deficiency prevalence $(68.1 \%)$ than medical students $(31.9 \%)$. The findings of this study shows that there was no significant difference between study levels in terms of prevalence of vitamin $D$ deficiency ( $p$ value $=0.068$ ). The findings of this study shows that there was a significant difference between single students and married students in terms of prevalence of vitamin $D$ deficiency ( $p$ value $=0.039$ ), single students had more vitamin D deficiency prevalence (73.7\%) married students $(26.3 \%)$. The findings of this study shows that there was a significant difference between countries in terms of prevalence of vitamin D deficiency ( $p$ value $=0.036$ ).

Table 1 summarize the prevalence of vitamin D deficiency for each country.

Table 1. Prevalence of vitamin D deficiency $(n=699)$.

\begin{tabular}{ll}
\hline $\begin{array}{l}\text { Country (Total number } \\
\text { students) }\end{array}$ & $\begin{array}{l}\text { Vitamin } \\
\text { (Percentage) }\end{array}$ \\
\hline Levant and Iraq (262) & $69(25.6 \%)$ \\
\hline Europe (177) & $93(34.4 \%)$ \\
\hline Gulf countries (114) & $68(25.5 \%)$ \\
\hline Africa (73) & $19(7 \%)$ \\
\hline Turkey and Cyprus (59) & $18(6.7 \%)$ \\
\hline USA and Canada (14) & $3(1.1 \%)$ \\
\hline
\end{tabular}

\section{Causes of vitamin D deficiency}

Majority of student's $(65.8 \%, n=460)$ linked their vitamin D deficiency to lack of sun exposure. 188 students linked their vitamin $\mathrm{D}$ deficiency to the diet and the rest of students linked their vitamin $\mathrm{D}$ deficiency to the financial issues.

\section{Prevalence of depression and its symptoms}

The findings of this study found that majority of students $(99.9 \%)$ in this study had depression. 
The findings of this study found that there was no association between depression and vitamin $\mathrm{D}$ depression ( $\mathrm{p}$ value $=0.386$ ). Table 2 summarize the depression severity classifications among students. Table 3 summarize the depression symptoms among students.

Table 2. Depression severity classifications among students ( $n=699)$.

\begin{tabular}{ll}
\hline Depression severity type & Frequency (Percentage) \\
\hline No depression & $1(0.1 \%)$ \\
\hline Minimal depression & $59(8.4 \%)$ \\
\hline Mild depression & $151(21.6 \%)$ \\
\hline Moderate depression & $142(20.3 \%)$ \\
\hline Moderate severe depression & $188(26.9 \%)$ \\
\hline Severe depression & $158(22.6 \%)$ \\
\hline
\end{tabular}

The findings of this study shows that there was a significant difference between the severe groups of depression and other classes in terms of prevalence of vitamin D deficiency ( $p$ value $=0.000$ ). Students with severe depression had more vitamin $\mathrm{d}$ deficiency $(67.1 \%)$ than others $(32.9 \%)$. The findings of this study shows that there was a significant difference between the severe or moderate severe groups of depression and other classes in terms of prevalence of vitamin $\mathrm{D}$ deficiency $(\mathrm{p}$ value $=0.000)$. Students with severe or moderate depression had more vitamin d deficiency $(56.6 \%)$ than others $(43.4 \%)$. The findings of this study shows that there was no significant difference between males and females in terms of severity of depression ( $p$ value $=0.650$ ). Results shows that females had more severe depression $(54 \%, n=187)$ than males $(46 \%, n=159)$. The findings of this study shows that there was no significant difference between medical students and non-medical students in terms of severity of depression ( $p$ value $=0.213$ ). The findings of this study shows that there was no significant difference between study levels in terms of prevalence of vitamin $D$ deficiency ( $p$ value $=0.467$ ). The findings of this study shows that there was no significant difference between males and females in terms of severity of depression ( $p$ value $=0.383$ ). The findings of this study shows that there was a significant difference between countries in terms of severity of depression ( $p$ value $=0.000$ ). Majority of severe depression students were from Levant and Iraq (35\%, $\mathrm{n}=121)$; followed by Europe $(32.4 \%, \mathrm{n}=112)$; Gulf countries (19.7\%, $n=68)$; Africa (6.9\%, $n=24)$; Turkey and Cyprus $(4 \%$, $\mathrm{n}=14)$ and America and Canada $(2 \%, \mathrm{n}=7)$.

Table 3. Depression symptoms evaluation among students $(n=699)$.

\begin{tabular}{|c|c|c|c|c|c|}
\hline S. No & Question & Not at all & Several days & $\begin{array}{l}\text { More than half } \\
\text { the days }\end{array}$ & $\begin{array}{l}\text { Nearly } \\
\text { day }\end{array}$ \\
\hline 1 & Little interest or pleasure in doing things & $41(5.9 \%)$ & $259(37.1 \%)$ & $249(35.6 \%)$ & $150(21.5 \%)$ \\
\hline 2 & Feeling down, depressed, or hopeless & $57(8.7 \%)$ & $233(33.3 \%)$ & $267(38.2 \%)$ & $142(20.3 \%)$ \\
\hline 3 & Trouble falling asleep, staying asleep, or sleeping too much & $78(11.2 \%)$ & $211(30.2 \%)$ & $202(28.9 \%)$ & $208(29.8 \%)$ \\
\hline 4 & Feeling tired or having little energy & $52(7.4 \%)$ & $209(29.9 \%)$ & 209 (29.9\%) & $229(32.8 \%)$ \\
\hline 5 & Poor appetite or overeating & $103(14.7 \%)$ & $211(30.2 \%)$ & $226(32.3 \%)$ & $159(22.7 \%)$ \\
\hline 6 & $\begin{array}{l}\text { Feeling bad about yourself, feeling that you are a failure, or feeling that you have } \\
\text { let yourself or your family down }\end{array}$ & 139 (19.9\%) & $186(26.6 \%)$ & $188(26.9 \%)$ & $186(26.6 \%)$ \\
\hline 7 & $\begin{array}{l}\text { Trouble concentrating on things such as reading the newspaper or watching } \\
\text { television }\end{array}$ & $163(23.3 \%)$ & $206(29.5 \%)$ & $194(27.8 \%)$ & $136(19.5 \%)$ \\
\hline 8 & $\begin{array}{l}\text { Moving or speaking so slowly that other people could have noticed. Or being so } \\
\text { fidgety or restless that you have been moving around a lot more than usual }\end{array}$ & $230(32.9 \%)$ & $185(26.5 \%)$ & $175(25 \%)$ & $109(15.6 \%)$ \\
\hline 9 & $\begin{array}{l}\text { Thinking that you would be better off dead or that you want to hurt yourself in some } \\
\text { way }\end{array}$ & $358(51.2 \%)$ & $225(32.2 \%)$ & $80(11.4 \%)$ & $36(5.2 \%)$ \\
\hline
\end{tabular}

\section{Discussion}

This study explored the association between vitamin D deficiency and depression among university students from 39 different countries. The findings of this study shows that 270 students $(38.6 \%)$ had vitamin D deficiency. Vitamin D deficiency nowadays a worldwide problem and affecting males and females any age [1-4,13-18].The prevalence of vitamin D deficiency in this study different between males and females and this could be due to many factors such as clothes type, duration of sun exposure and this is similar to other studies worldwide [13-18]. The findings of this study shows that there was a significant difference between countries in terms of prevalence of vitamin $\mathrm{D}$ deficiency $(\mathrm{P}$ value $=0.036)$.

The findings of this study shows that the prevalence of vitamin D deficiency were different between countries. Students from Levant and Iraq, Europe, Gulf countries had more vitamin d deficiency prevalence than those form Africa, Turkey and Cyprus and USA and Canada. This could be due to the number of participant's students was low in those countries. The 
findings of this study show that the majority of student's linked their vitamin D deficiency to lack of sun exposure; diet and financial factors. This is similar to the previous studies worldwide [13-18]. Literature reported that the main source of vitamin $\mathrm{D}$ is sun exposure and due to many reasons majority of people worldwide can't obtain their required vitamin D from sun [13-18]. The findings of this study found that majority of students $(99.9 \%)$ in this study had depression. worldwide found that depression is common in university students [14-18]. The findings of this study show that females had more severe depression than males. This finding consisted with world health organization (WHO) report 2018 that the prevalence of depression among females were higher than males [19]. Another two studies in Unites States and Germany found that females had more depression than males [20,21]. The findings of this study found that there was no association between depression and vitamin $\mathrm{D}$ depression. On the other hand, the findings of this study show that there were significant associations between the severity of depression and vitamin D deficiency. The previous studies vary in their results as many reported that there were an association between depression and vitamin $\mathrm{D}$ deficiency and others reported that there were no associations between depression and vitamin $\mathrm{D}$ deficiency [5,22-27]. The findings of this study show that there was a significant difference between countries in terms of severity of depression. The previous study reported that the prevalence of depression is different from one country to another with high prevalence in the Middle East countries, North Africa countries, South Asia than other countries worldwide [28].

\section{Conclusion}

The current study shows that there was no association between vitamin D deficiency and depression. On the other hand, there were significant associations between the severity of depression and vitamin D deficiency. Lack of sun exposure; diet and financial factors were the causes of vitamin D deficiency in this study. Further studies are highly recommended to investigate the causes of depression among students.

\section{Acknowledgement}

The authors would like to thank the patients for their participation in this study.

\section{Conflicts of Interest}

No competing financial interests exist.

\section{References}

1. Holick MF. Vitamin D deficiency. N Engl J Med 2007; 357 : 266-281.

2. Gordon CM, DePeter KC, Feldman HA, Grace E, Emans SJ. Prevalence of vitamin D2 deficiency among healthy adolescents. Arch Pediatr Adolesc Med 2004; 158: 531-537.
3. Lips P, Hosking D, Lippuner K, Norquist JM, Wehren L, Maalouf G, Ragi-eis S, Chandler S. The prevalence of vitamin D inadequacy amongst women with osteoporosis: An international epidemiological investigation. J Intern Med 2006; 260: 245-254.

4. Melamed ML, Michos ED, Post W, Astor B. 25hydroxyvitamin D levels and the risk of mortality in the general population. Arch Intern Med 2008; 168: 1629-1637.

5. Zhao G, Ford ES, Li C, Balluz LS. No Associations between Serum Concentrations of 25-hydroxyvitamin D and parathyroid hormone and depression among US adults. Br J Nutr 2010; 20: 1-7.

6. Lee DM, Tajar A, O'Neill TW, O'Connor DB, Bartfai G, Boonen S, Bouillon R, Casanueva FF, Finn JD, Forti G, Giwercman A, Han TS, Huhtaniemi IT, Kula K, Lean ME, Punab M, Silman AJ, Vanderschueren D, Wu FC, Pendleton N. Lower vitamin D levels are associated with depression among community-dwelling European men. J Psychopharmacol 2011; 25: 1320-1328.

7. Cherniack EP, Troen BR, Florez HJ, Roos BA, Levis S. Some New Food for Thought: The role of Vitamin D in the mental health of older adults. Curr Psychiatry Rep 2009; 11: 12-19.

8. Jorde R, Snev M, Figenschau Y, Svartberg J, Waterloo K. Effects of vitamin D supplementation on symptoms of depression in overweight and obese subjects: randomized double blind trial. JAMA Intern Med 2008; 264: 599-609.

9. American Psychiatric Association. Diagnostic and Statistical Manual of Mental Disorders (DSM-5). 5th edn. 2013.

10. Penckofer S, Kouba J, Byrn M, Ferrans CE. Vitamin D and depression: where is all the sunshine? Issues Ment Health Nurs 2010; 31: 385-93.

11. Kroenke K, Spitzer RL. The PHQ-9: a new depression diagnostic and severity measure. Psychiatr Ann 2002; 32: 509-15.

12. Kroenke K, Spitzer RL, Williams JBW. The PHQ-9: validity of a brief depression severity measure. J Gen Intern Med 2001; 16:606-13.

13. Holick MF, Chen TC. Vitamin D deficiency: a worldwide problem with health consequences. Am J Clin Nutr 2008; 87: 1080S-1086S.

14. Sulaiman AH, Abukanna AM, Alenezy AA, Balla AA. Prevalence of Vitamin D Deficiency among university female students in Northern Border Region of Kingdom of Saudi Arabia (KSA). Ann Med Health Sci Res 2017.

15. Kaddam IM, Al-Shaikh AM, Abaalkhail BA, Asseri KS, Al-Saleh YM, Al-Qarni AA, Al-Shuaibi AM, Tamimi WG, Mukhtar AM. Prevalence of vitamin D deficiency and its associated factors in three regions of Saudi Arabia: A crosssectional study. Saudi Med J 2017; 38: 381.

16. Moussaviv M, Heidarpour R, Aminorroaya A, Pournaghshband Z, Amini M. Prevalence of vitamin D deficiency in Isfahani high school students in 2004. Horm Res Paediatr 2005; 64: 144-181. 
17. Faghih S, Abdolahzadeh M, Mohammadi M, Hasanzadeh J. Prevalence of vitamin d deficiency and its related factors among university students in shiraz, iran. Int J Prev Med 2014; 5: 796.

18. Al Anouti F, Thomas J, Abdel-Wareth L, Rajah J, Grant WB, Haq A. Vitamin D deficiency and sun avoidance among university students at Abu Dhabi, United Arab Emirates. Dermatoendocrinol 2011; 3: 235-9.

19. https://www.who.int/news-room/fact-sheets/detail/ depression.

20. Kuehner C. Gender differences in unipolar depression: an update of epidemiological findings and possible explanations. Acta Psychiatr Scand 2003; 108:163-174.

21. Saluja G, Iachan R, Scheidt PC, Overpeck MD, Sun W, Giedd JN. Prevalence of and risk factors for depressive symptoms among young adolescents. Arch Pediatr Adolesc Med 2004; 158: 760-765.

22. Hoogendijk WJ, Lips P, Dik MG, Beekman AT, Penninx BW. Depression is associated with decreased 25hydroxyvitamin D and increased parathyroid hormone levels in older adults. Arch Gen Psychiatry 2008; 65: 508-512.

23. Jorde R, Waterloo K, Saleh F, Haug E, Svartberg J. Neuropsychological function in relation to serum parathyroid hormone and serum 25-hydroxyvitamin D levels. The Tromso study. J Neurol 2006; 253: 464-470.

24. Pan A, Ling Lu, Franco OH, Zhizie Y, Huaixing Li, Lin X. Association between depressive symptoms and 25hydroxyvitamin D in middle-aged and elderly Chinese. J Affect Disord 2009; 118: 240-243.
25. Wilkins $\mathrm{CH}$, Sheline YI, Roe CM, Birge SJ, Morris JC. Vitamin D deficiency is associated with low mood and worse cognitive performance in older adults. Am J Geriatr Psychiatry 2006; 14: 1032-1040.

26. Anglin RES, Samaan Z, Walter SD, McDonald SD. Vitamin D deficiency and depression in adults: systematic review and meta-analysis. $\mathrm{Br} \mathrm{J}$ Psychiatry 2013; 202: 100-107.

27. Milaneschi Y, Hoogendijk W, Lips P, Heijboer AC, Schoevers R, Van Hemert AM, Beekman AT, Smit JH, Penninx BW. The association between low vitamin D and depressive disorders. Mol Psychiatry 2014; 19: 444.

28. Ferrar AJ, Charlson FJ, Norman RE, Patten SB, Freedman G, Murray CJ, Vos T, Whiteford HA. Burden of depressive disorders by country, sex, age, and year: findings from the global burden of disease study 2010. PLoS Medicine 2013; 10: e1001547.

\section{*Correspondence to}

Yaser Mohammed Al-Worafi

College of Pharmacy

University of Science and Technology of Fujairah

Fujairah

UAE 